PRE-CAMBRIAN

\section{Holocene Activity?}

from our Geomagnetism Correspondent

IT is not very often that 3,000 year old man gets a chance to make a contribution to twentieth century geology; and seldom do engineering and archaeology combine to suggest a fundamental reassessment of geological activity in Pre-Cambrian areas. The Volta River Project in Ghana, however, has provided examples of not one but both of these unlikely events, as Thompson has now described (Bull. Geol. Soc. Amer., 81, 3759; 1970).

Detailed study of the Volta River to select a suitable site for a dam was begun in 1959. The reason for choosing the Volta was simply that it is Ghana's largest water course-its principal stem and many tributaries provide a drainage pattern which covers about 75 per cent of the country's surface area. Other streams are relatively short; and most of them flow west of Accra where they run down to the Gulf of Guinea across a gently sloping plain developed from the oldest Pre-Cambrian rocks. Much of the lower course of the Volta also flows across Pre-Cambrian rocks; but there the resemblance ends. For, whereas the trends of the other Ghanaian rivers are controlled by the structure of the bedrock, it has been shown that the course of the Volta is not.

And that is not the only strange feature of the lower Volta. At Ajena, a few miles upstream from where the dam was finally sited (Akosombo), the river was only about 5 feet deep (before the dam was built); and 11 miles downstream at Senchi the water was so shallow that it could be crossed by wading. Between these points, however, the stream bed dips rapidly to give a maximum depth of about 200 feet and thus assumes what Thompson calls a "lake-like condition" with a jagged bottom profile. It is clear therefore that whatever other geological process might have produced this part of the river basin, it was certainly not normal erosion.

So what was the origin of this unusual river bed? Surprisingly, the clues come chiefly from history and archaeology. Legends to the effect that Earth tremors have caused panic among the local tribes have been passed from generation to generation to become part of the cultural history of the region. Legends alone do not, of course, rate very highly as scientific evidence; but backed by the record of a real earthquake which occurred near Accra in 1937, they suggest that earthquake activity is no stranger to the area in recent times.

In support of this view, Thompson also quotes a nice piece of archaeological evidence. Before construction of the dam was begun several small rock islands protruded above the water surface, but, during construction, it was necessary to lower the water surface by about 35 feet, a process which revealed, at 32 feet below the normal water level, a man made carving which was dated as 3,000 years old. This would seem to indicate that one side of the Accra fault, which roughly coincides with the Ghanaian coast along the Gulf of Guinea and which marks the downstream boundary of the "lake-like" basin, must have undergone a vertical displacement of about 32 feet during the pats 3,000 years. In other words, the deep basin and its peculiar profile were almost certainly formed by recent (post-Pleistocene) tectonic activity.

As a result of these discoveries during construction, the design of the Volta dam was rapidly amended to allow greater resistance to earthquakes. But the most interesting part of this story is why such a possibility was not foreseen. The reason is, of course, that the lower Volta runs over Pre-Cambrian rocks; and Pre-Cambrian regions are traditionally thought of as stable areas free from faulting and thus not subject to earthquakes. Perhaps, as Thompson suggests, this view is outdated, especially because there is also evidence of recent activity in the Brazilian Pre-Cambrian shield. Near São Paulo, for example, road cuttings have exposed strong displacements of Pleistocene and Holocene continental basin fills by faults which project upwards through the Pre-Cambrian schists and gneisses and strongly offset the younger material. In the light of this evidence Thompson goes so far as to suggest that many of the Earth's Pre-Cambrian areas should now be classified as earthquake hazards "as severe as California".

\section{PHOTOSYNTHESIS \\ Enhancement Annulled}

by our Plant Physiology Correspondent THE structure of plastids is so closely bound up with their function that it is hardly surprising that recent experiments have shown the well known enhancement of photosynthesis by short wavelength light to be annulled when chloroplasts were converted from the lamellar to the homogeneous state. Nevertheless, it is a great deal easier to make the insides of chloroplasts homogeneous than it is to explain what changes take place in their biochemistry after the transformation. The answers to some of the questions posed may considerably advance our understanding of the photosynthetic machinery.

Chloroplasts in most flowering plants have a characteristic appearance ; ovoid organelles containing organized arrays of membranes. These membranes are of two sorts, the grana, which are deeply pigmented and look like cylin-

\title{
Membrane Protein and Sodium Inactivation
}

THE action potential of nerve fibres results from a large transient increase in the sodium permeability of the membrane which gives rise to a flow of sodium ions from the external medium into the interior of the fibre. The increase in permeability is short lived; it is abolished within a few milliseconds by a process known as inactivation. This process is largely responsible for the short duration of the nervous impulse and for the well known refractory period following each action potential. Very little is so far known, however, about the molecular events in the membrane which are responsible for the inactivation of the sodium permeability. E. Rojas and C. Armstrong now show in next Wednesday's Nature New Biology that inactivation depends on the intactness of a membrane protein; internal treatment of nerve fibres with the proteolytic enzyme pronase completely eliminates inactivation.

Intracellular perfusion of giant axons of the Chilean squid Dosidicus gigas (diameter more than $1 \mathrm{~mm}$ ) was carried out using the well established method consisting of removing part of the axoplasm and perfusing the interior of the fibre with an artificial salt solution. The membrane currents were recorded with the voltage clamp technique. 30 min perfusion with a salt solution containing the enzyme pronase $\left(1 \mathrm{mg} \mathrm{ml} .^{-1}\right)$ drastically altered the membrane currents-the normal transient sodium inward current was replaced by a sustained inward current which declined only very little during a $15 \mathrm{~ms}$ pulse. It was most clearly seen after eliminating the overlapping potassium current by tetraethylammonium chloride. At the end of the pulse a large inward tail current occurred. Rojas and Armstrong found that the sustained inward current and the tail current could be blocked by tetrodotoxin, the specific inhibitor of the sodium permeability.

The effect of pronase on sodium inactivation was found to be fairly selective. Activation of the sodium permeability remained essentially intact. The potassium permeability was normal provided the treatment with pronase was not too prolonged. Thus, Rojas and Armstrong's work supports the idea that sodium and potassium ions pass through the membrane in separate channels. 